\title{
Analytic Back Calculation of Debris Flow Damage Incurred to a Masonry Building: The Case of Scaletta Zanclea 2009 Event
}

\author{
Hossein Soleimankhani ${ }^{1, a}$, Stefano Carozza ${ }^{1}$, Giuseppe T. Aronica ${ }^{2}$, Fatemeh Jalayer ${ }^{1}$, and Antonino Recupero ${ }^{2}$ \\ ${ }^{1}$ Department of Structures for Engineering and Architecture, University of Naples "Federico II", Naples, Italy \\ ${ }^{2}$ Department of Civil, Computer, Construction, Environmental Engineering and Applied Mathematics, University of Messina, \\ Messina, Italy
}

\begin{abstract}
In an attempt to do a back analysis of the damages caused to a nineteenth century masonry structure due to the October 2009 flash flood/debris flow event in Scaletta Zanclea, the flood discharge hydrograph is reconstructed in the ungauged conditions. The hydrograph for the solid discharge is then estimated by scaling up the liquid volume to the estimated debris volume. The debris flow diffusion is simulated by solving the differential equations for a single-phase 2D flow employing triangular mesh elements, taking into account also the channelling of the flow through the buildings. The damage to the building is modelled, based on the maximum hydraulic actions caused by the debris flow, using 2D finite shell elements to model the building, boundary conditions provided by the openings, floor slab, orthogonal wall panels, and the foundation. The reconstruction of the event and the damages to the case-study building confirms the location of the damages induced by the event.
\end{abstract}

\section{Introduction}

These flash flood is defined as a flood which follows shortly (i.e. within a few hours) after a heavy or excessive rainfall event (Borga et al. 2007; Gaume 2008; Georgakakos 1986; Sweeney 1992) and consequently, the important hydrologic processes are occurring on the same spatial and temporal scales as the intense precipitation. These kind of events represent an important problem in Europe, and especially in many Mediterranean catchments. As a consequence of a sudden increase in water depths and flow velocities, they can cause serious damages and economic losses. For example, an estimated $€ 1.2$ billion Euro damages were caused in the Gard (France) 2002 single flash flood event (Huet et al. 2003), € 65 million Euro in the 2000 Magarola (Spain) flash flood (Botija et al. 2001), $€ 300$ million Euro in the 1994 Pinios (Greece) flash flood (Gaume et al. 2004) and $€ 4.6$ million Euro in the 2007 Mastroguglielmo (Italy) flash flood event (Aronica et al. 2009).

Past flash floods and debris flow events have often caused high numbers of casualties; over 80 people, for example, lost their lives in the 1996 Biescas flood in Spain (Alcoverro et al. 1999), 47 people died in the flash flood on the Malá Svinka River in Slovakia in 1998, 23 people were killed in the Gard 2002 flood, 2 people died in the flash flood and debris flow on Cable Canyon in San Bernardino County in California in 2003 (Restrepo et al. 2009) and 19000 people were killed in the Cordillera de la Costa, Vargas (Venezuela) flash flood and debris flow disaster in 1999 (Larsen et al. 2002).

\footnotetext{
${ }^{\mathrm{a}}$ Corresponding author: fatemeh.jalayer@unina.it
}

As occurs in practically all Mediterranean countries, most of the catchments in the North-East part of Sicily (Italy) are small, with a steep slope, and characterised by short concentration times. Moreover, most of the slopes are poorly vegetated and, consequently, rainfall that is normally absorbed by vegetation can run off almost instantly. All these characteristics make those catchments prone to flash flood formation, as demonstrated by events that occurred in the area around Messina in recent years. The events which took place on October 25th, 2007 in the Mastroguglielmo catchment located in the Ionic sea coast, on December 11th, 2008 in the Elicona catchment on the Tyrrhenian sea coast and on October 1st, 2009 in Racinazzi and Giampilieri catchments on the Ionic sea coast are examples of flash floods and debris flow events that caused not only significant economic damages to property, buildings, roads and bridges but also, in the case of the October 1st, 2009 flash flood event, loss of human life (Aronica et al. 2010; Aronica et al. 2012).

During this last event, in fact, a devastating flood was caused by a very intense rainfall concentrated over Eastern Sicily; particularly, affecting the area of Messina and was responsible for the destruction of numerous structures and goods and for 38 casualties. Many villages were involved such as Giampilieri, Scaletta Zanclea, Altolia Superiore and the damages were estimated close to 550 million Euros (Regional Department of Civil Protection for Sicily, 2009).

The flash-flood and debris flow phenomena can potentially cause significant damage to the buildings due 
to (Kelman and Spence 2004; Zanchetta et al. 2004, Smith 1994): a) the hydro-dynamic component of the forces applied by the flow (as this phenomenon is characterized by high velocity values); b) the hydro-static component of forces applied by the flow; c) the accidental impact caused by flow-borne materials (e.g., rocks, trees, cars, pipes, etc.); d) uplifting forces (buoyancy); e)erosion, capillary effects, etc.. Depending on the position of a building with respect to the flow and the intensity of the event (e.g., the flow depth and velocity in correspondence with the building), the building may undergo significant non-structural and structural damage (Faella and Nigro 2003). The type of damage caused by the debris flow depends also on the building type. For example, the reinforced concrete frame structures may undergo damage both in their primary load-bearing system (the frame) and also in the secondary load bearing system (infill panels, Mavrouli et al. 2014). For masonry structures instead, the load-bearing wall panels are going to be subjected to the debris flow impact. Another important aspect, common to all structural types, is the role of the openings as the weakest link within the building. Usually, the doors and windows are the first elements to be swept away by the flow letting the flow infiltrate inside the building (Mavrouli et al. 2014). In the recent years, quite a few studies have been performed with the aim of evaluating the building vulnerability to debris flow based on expert judgment (Bell and Glade 2004) and based on observed damage and incurred losses due to the past events (Akbas et al. 2009; Fuchs et al. 2007; Quan Luna et al. 2011). There have been few attempts for quantifying the building vulnerability to debris flow through analytical models. Nigro and Faella (2010) have classified the various resisting mechanisms to debris flow for reinforced concrete frames and masonry structures. They have used limit analysis in order to calculate the critical flow velocity that can activate a mechanism in the structure. Haugen and Kaynia (2008) have proposed a methodology for calculating the dynamic response of an equivalent single degree of freedom system to debris flow impact. On a different note, De Risi et al. (2013) have quantified the vulnerability of non-engineered buildings (substandard masonry) to flood actions by creating an elastic finite element model of individual building wall panels considering the position and the quality of the openings.

This work strives to re-construct the damages caused to a nineteenth century masonry building that was heavily damaged by the Scaletta Zanclea event. Given the lack of measurements for the flow discharge, the rainfall-runoff method together with the curve-number method was employed in order to estimate the liquid discharge due to the intense rainfall of 1 October 2009, using the kinematic unit hydrograph. The debris flow discharge was then estimated based on debris flow volume evaluations performed on similar catchments in the same zone and by applying the Takahashi amplification factor. Debris flow propagation was then simulated by solving the $2 \mathrm{D}$ differential equations of motion for a single-phase liquid, using finite elements and considering the obstacle caused by the built environment in modelling the boundary conditions. This led to deriving the time-history and the envelope of the hydraulic forces (hydro-static + hydro-dynamic) applied to the case-study building. The case-study masonry building was modelled by using elastic 2D shell elements, taking into account all the doors and windows openings, all the orthogonal wall panels, the floor slab of the first story as a rigid diaphragm and the boundary conditions imposed by foundations. The approach adopted herein for vulnerability assessment is similar to that of De Risi et al. (2013) for simulating the local building damage due to the flow. The compressive strength of the masonry wall was estimated by performing destructive in-situ compression tests on wall panels of similar buildings in the zone.

\section{Main characteristics of study area}

The small village of Scaletta Zanclea is located on the Ionic sea in the North-Eastern part of Sicily, and $20 \mathrm{~km}$ in the south-eastern side of the city of Messina. The village is crossed by the Racinazzi torrent whose catchment has an area of approximately $1.6 \mathrm{~km}^{2}$ with elevations that range between 0 and $790 \mathrm{~m}$ a.s.l. and an average value of $384 \mathrm{~m}$ a.s.l. (Figure 1). The topography is very rugged and the slope is steep (average value is 0.18 ) as is that of a number of its tributaries, some of which are incised into narrow pathways as they approach the main channel whose length is about $3.3 \mathrm{~km}$.

The catchment is predominantly rural with grassland and crop cultivation $(46 \%)$ and shrubs and sparse forest $(42.4 \%)$ in the upper mountainous part while the areas $(7.3 \%)$ in the valley floor are highly urbanized (Scaletta Zanclea). Moreover, several slopes suffered local or global instability processes in the past and the stability conditions of the shallowest portions of most of rock slopes are in some cases unsatisfactory due to the poor geotechnical properties of the cover soils.

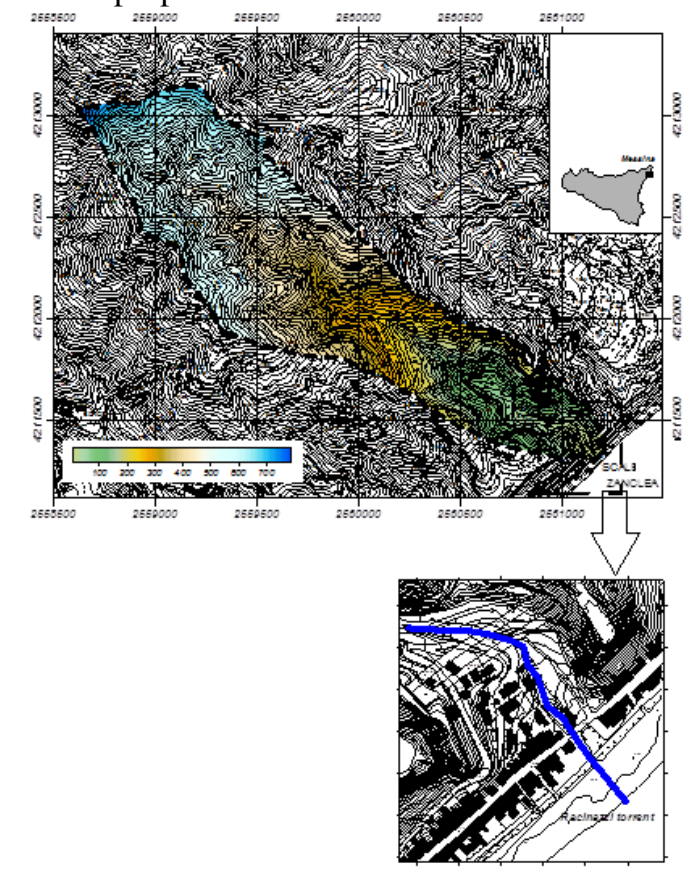

Figure 1. Study area (Racinazzi catchment, left; Scaletta Zanclea village, right). 
The climate is typical Mediterranean, with rainfall events (mainly convective) characterized by short durations and high intensities during the wet season (October - April) and few events during the dry season (May - September). The mean annual rainfall is about $970 \mathrm{~mm}$ with around $84 \%$ in the wet season and $16 \%$ in the dry season.

\section{The 2009 event description}

On the afternoon of October 1st, 2009, a deep cyclone developed in the Southern part of the Mediterranean basin producing an intense rainstorm over Sicily, particularly affecting the area of Messina. The flash flood and debris flow triggered by the consequent heavy rainfall event locally involved property, buildings, roads and bridges and blocked the traffic for many hours; 38 people lost their lives and damages close to $550 \mathrm{M}$ Euros have been estimated (Regional Department of Civil Protection for Sicily, 2009).

During the late evening, the village of Scaletta Zanclea was hit by a large debris flow coming from Racinazzi torrent that caused the collapse of some buildings and loss of lives. The A/18 Messina-Catania Motorway, the State Road 114 and the GiampilieriScaletta rail line were closed off due to the landslides.

Rainfall maps (Aronica et al. 2010) show how the storm covered the southern part of the city of Messina and was concentrated on the Ionic sea coast and mainly in the area around Giampilieri and Scaletta Zanclea. The event happened over a few hours; more than $220 \mathrm{~mm}$ of rain fell in less than 4 hours with a peak of about 120 $\mathrm{mm} / \mathrm{hr}$ in 10-minutes (Figure 2).

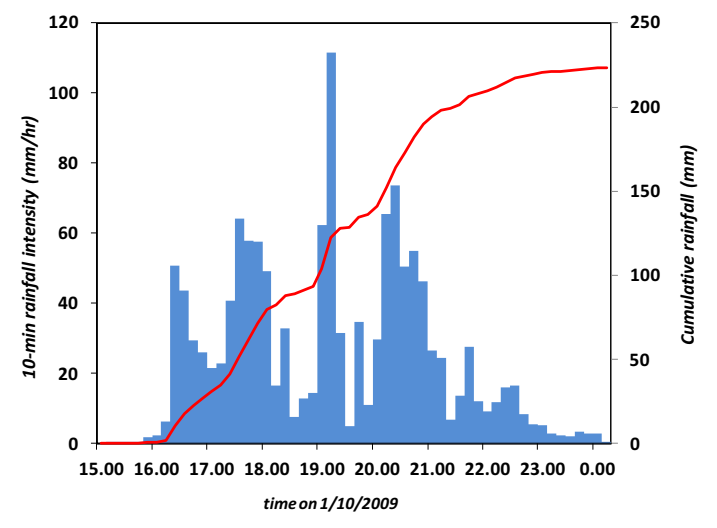

Figure 2. 2009 event recorded hyetograph.

\subsection{Flood/Debris flow hydrograph reconstruction}

Given the lack of any discharge measurements discharge data, as no flow gauge is located within the Racinazzi catchment for the reconstruction of the flood hydrograph (liquid discharges), a simple lumped rainfallrunoff model based on a Kinematic Instantaneous Unit Hydrograph IUH for flood routing and Soil Conservation Service-Curve Number (SCS-CN) method implemented on the basis of the "time dependent" formulation (Chow et al. 1988) for runoff generation was used (Aronica et al. 2012). The Kinematic IUH was calculated using time- area curve derived for the catchment apart the Digital Elevation Model and a value of the concentration time equal to 40 minutes from Wooding formula for a single plane. Land use maps from Corine project and soil type maps were available allowing to derive a lumped value of $\mathrm{CN}=80$ for high saturated conditions $(\mathrm{AMC}=\mathrm{III})$ used for the simulations.

The solid discharge hydrograph was simply derived by rescaling the liquid volume to the estimated debris volume using the Takahashi amplification coefficient (Takahashi 1991):

Post-event analysis and a comparison with similar events in a catchment close to the Racinazzi (Aronica et al. 2012) led to an estimation of solid debris volume around $0.54 \mathrm{Mm}^{3}$. Now, by considering an equilibrium solid concentration of 0.45 the resulting mixture volume is around $1.2 \mathrm{Mm}^{3}$ and the Takahashi amplification coefficient is equal to 4.5 . The resulting hydrographs are reported in Figure 3.

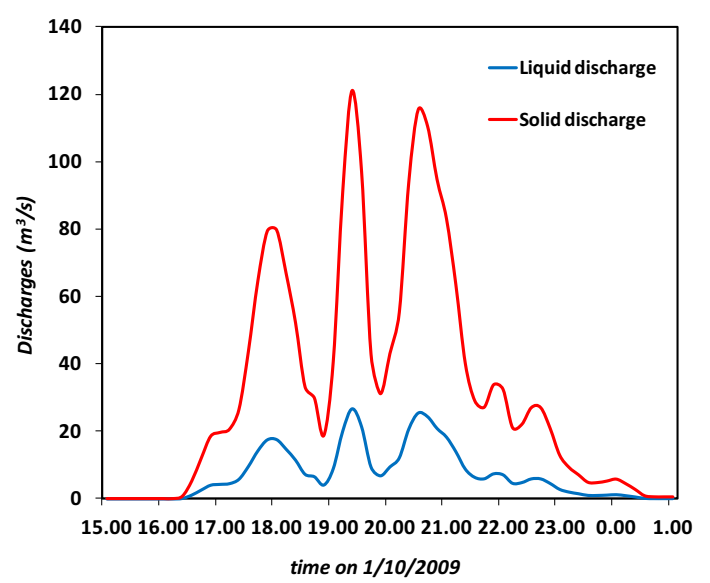

Figure 3. Reconstructed liquid and solid flood hydrograph.

\subsection{Debris flow propagation}

To simulate the propagation of the debris flow on the alluvial fan an hyperbolic single-phase fluid model in 2D form has been used (Aronica et al. 2012). This model is based on the DSV equation and it is capable of simulating the $2 \mathrm{D}$ flow of a single-phase fluid by considering a different set of equations for modeling friction terms instead of classical Chèzy formula:

$$
\begin{aligned}
& \frac{\partial H}{\partial t}+\frac{\partial(u h)}{\partial x}+\frac{\partial(v h)}{\partial y}=0 \\
& \frac{\partial(u h)}{\partial t}+g h \frac{\partial H}{\partial x}+g h J_{x}=0 \\
& \frac{\partial(v h)}{\partial t}+g h \frac{\partial H}{\partial y}+g h J_{y}=0
\end{aligned}
$$

where $H(t, x, y)$ is the free surface elevation, $u$ and $v$ are the $x$ and $y$ components of flow velocity, $h$ is the depth of debris flow, $J x$ and $J y$ are the friction terms in the $x$ and $y$ directions.

For modeling friction terms Takahashi (1991) equations have been here adopted according to the dilatants fluid hypothesis developed by Bagnold (1954). 
Hence, the friction terms are computed as the sum of two terms related to the shear stresses, i.e. turbulent and dispersive (Brufau et al. 2000; Naef et al. 2006):

$$
\begin{aligned}
& J_{x}=\frac{u \sqrt{u^{2}+v^{2}}}{\left(\frac{2}{5 d} \frac{1}{\lambda} h\right)^{2} \frac{1}{a_{B} \sin \varphi}\left[c+(1-c) \frac{\rho}{\rho_{s}}\right] g h} \\
& +\frac{n^{2} u \sqrt{u^{2}+v^{2}}}{h^{4 / 3}} \\
& J_{y}=\frac{v \sqrt{u^{2}+v^{2}}}{\left(\frac{2}{5 d} \frac{1}{\lambda} h\right)^{2} \frac{1}{a_{B} \sin \varphi}\left[c+(1-c) \frac{\rho}{\rho_{s}}\right] g h} \\
& +\frac{n^{2} v \sqrt{u^{2}+v^{2}}}{h^{4 / 3}}
\end{aligned}
$$

where $d$ is the mean diameter of the sediment particles, $\phi$ is the internal friction angle, $\lambda$ is the linear concentration equal to $c^{1 / 3} / c_{s}{ }^{1 / 3}-c^{1 / 3}$ where $c_{s}$ is the coarse fraction concentration in the static debris bed, $\rho_{s}$ is the density of the solid phase, $\rho$ is the density of interstitial fluid, $n$ is the Manning roughness.

The model equations are solved by using a finite element technique with triangular elements. The free surface elevation is assumed to be continuous and piecewise linear inside each element, where the unit discharges $u h$ and $v h$, in the $x$ and $y$ directions are assumed to be piece-wise constant. Blocks and other obstacles are treated as internal islands within the triangular mesh covering the entire flow domain. For more details on the model refer to Aronica et al. (1998) and (Aronica et al. 2012).

The definition of the finite element mesh boundary (Fig.3) was based upon the morphology of the study area in order to cover alluvial fan, to leave the blocks and the single houses out of the domain and to take in account internal barriers and hydraulic discontinuities. The total domain area is about $0.22 \mathrm{~km}^{2}$ and was discretized in 13419 triangular elements. The geometric features (x,y,z coordinates) of 7282 nodes have been derived from the Digital Elevation Map (DEM) with $2 \mathrm{~m}$ resolution (Fig.1). Regarding the parameters of the equations (2) expressing the friction terms the following values have been considered according to the results of a field survey carried out after the 2009 event: $d=2.5 \mathrm{~cm}, \phi=36^{\circ}, c=$ $0.43, c_{s}=0.58, \rho_{s}=2650 \mathrm{~kg} / \mathrm{m}^{3}, \rho=1000 \mathrm{~kg} / \mathrm{m}^{3}, a_{B}=$ 0.045 and $n=0.025 \mathrm{~m}^{-1 / 3} / \mathrm{s}$.

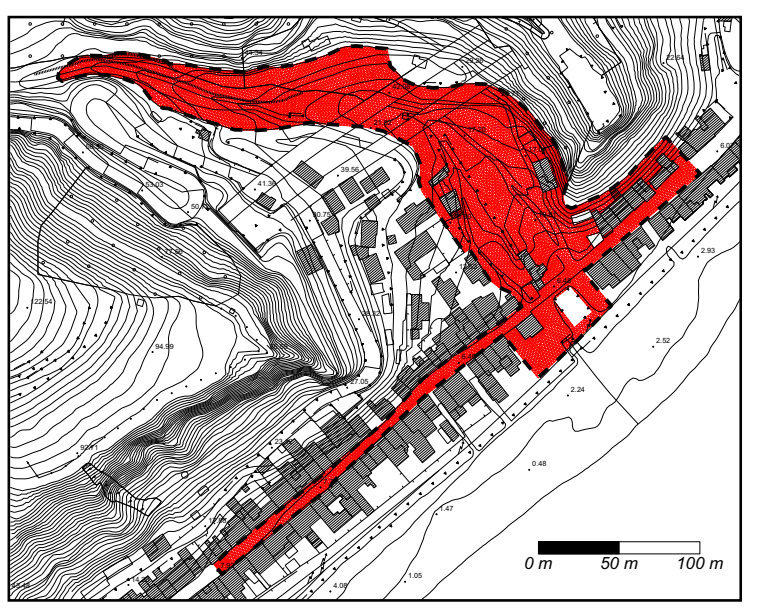

Figure 4. Layout of the Finite elements mesh used for the hydrodynamic simulations.

Given the reconstructed debris flow hydrograph (Figure 3), maximum values of flow depths and flow velocity modules were computed in each node and element of the computational domain. Their spatial distribution is reported respectively in Figure 5 and Figure 6.

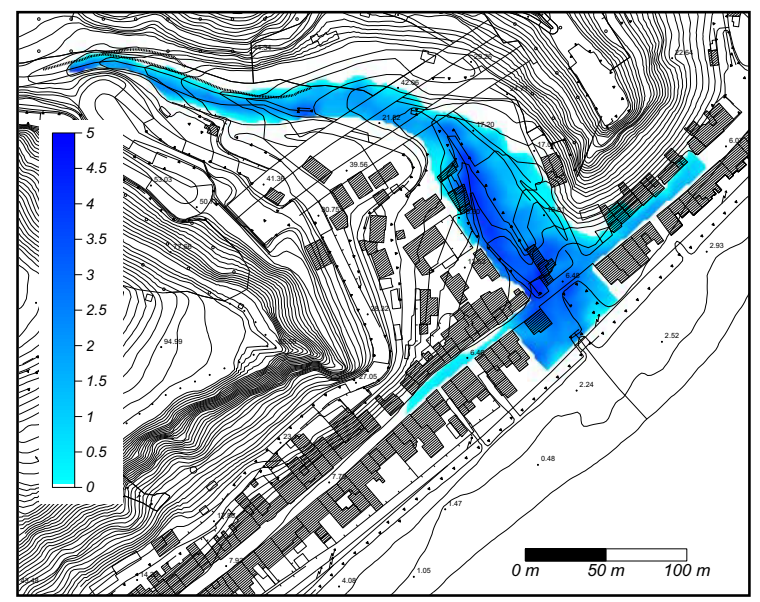

Figure 5. Map of maximum flow depths (colour scale in meters). 


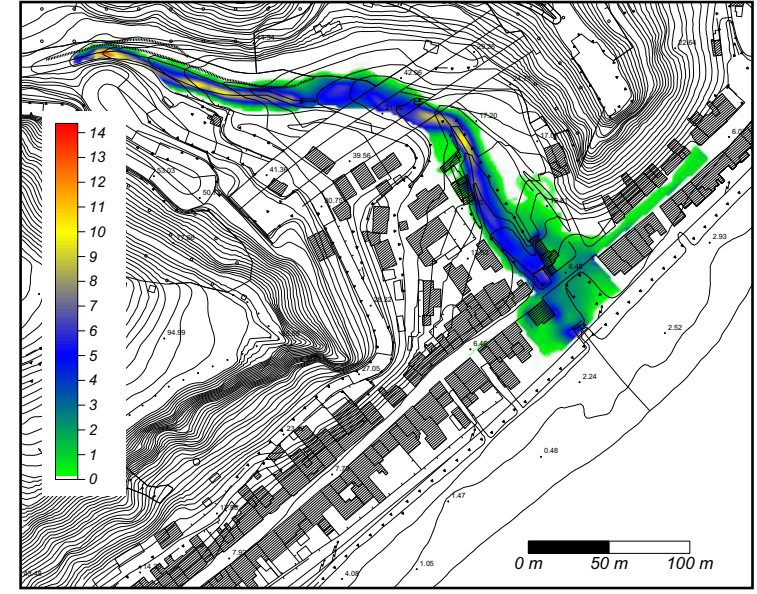

Figure 6. Map of maximum flow velocity modules (colour scale in $\mathrm{m} / \mathrm{s})$.

Moreover, for the purpose of this study the total hydrodynamic force per unit width (debris flow impact pressure) has been considered. This force can be calculated as follows (see e.g., Zanchetta et al. (2004)):

$$
S_{\text {tot }}=\rho_{m} h\left(u^{2}+v^{2}\right)+\frac{1}{2} \rho_{m} g h^{2}
$$

where $u$ and $v$ are the two orthogonal horizontal components of the debris flow velocity vector; $h$ is the depth of the flow and $\rho_{m}$ is the density of the solid-liquid mixture, $\rho_{m}=c \rho_{s}+(1-c) \rho$ (in this case about 1742.5 $\mathrm{Kg} / \mathrm{m}^{3}$ ).

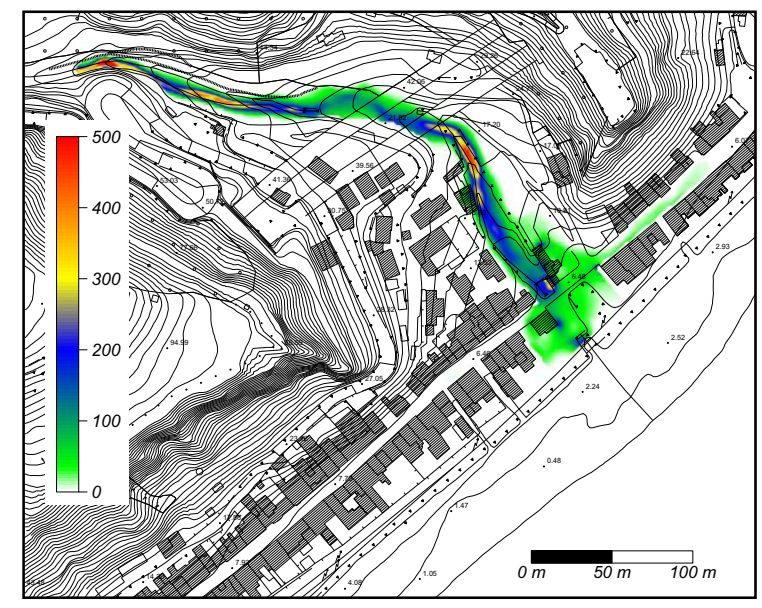

Figure 7. Map of maximum total hydrodynamic force for unit width (color scale in $\mathrm{kN} / \mathrm{m}$ )

Also, the force resulting from impact of the flow borne objects is calculated as follows:

$$
F_{D I}=\frac{\left(W_{D} / g\right) \times v_{D}}{t}
$$

Where $F_{D I}$ is the impact force, $W_{D}$ is weight of object, $v_{D}$ is velocity of object assumed to be equal to the $v_{\max }$, and $t$ is the duration of impact.

\section{Case study structure}

\subsection{The structure object of analysis}

The structure, object of this analysis, is situated in Scaletta-Zanclea town near Messina, on the road SS114 "Consolare Valeria" right next to the Racinazzi torrent (Figure 8).
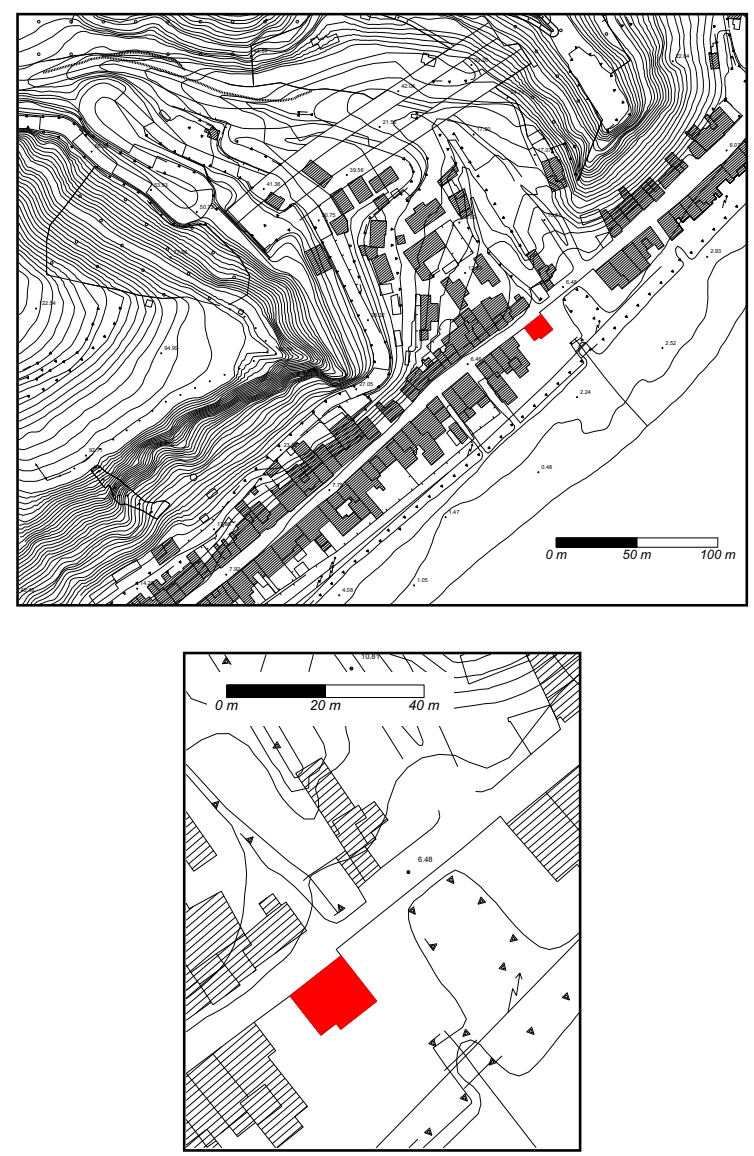

Figure 8. Location of the edifice analysed.

This edifice has been built at the end of 1800 and was restored after the 1908 Messina earthquake. It is composed of two levels; with a reinforced concrete slab in the first floor and a wooden roof with tiles. The structure is constituted by irregular masonry with fractured stone and parts of brick of little/medium size (Figure 9 and Figure 10). This type of masonry was very common in Messina area during the past until 1950 years when it has been substituted by masonry totally in brick. 


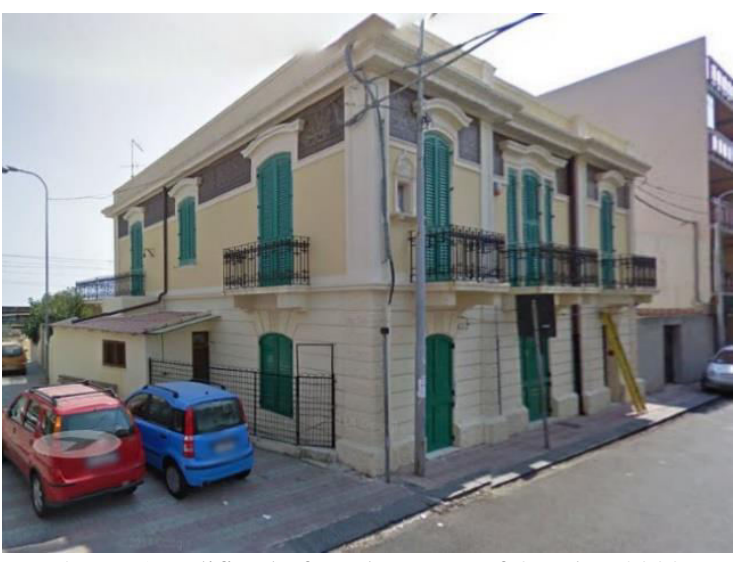

Figure 9. Edifice before the event of October 2009.

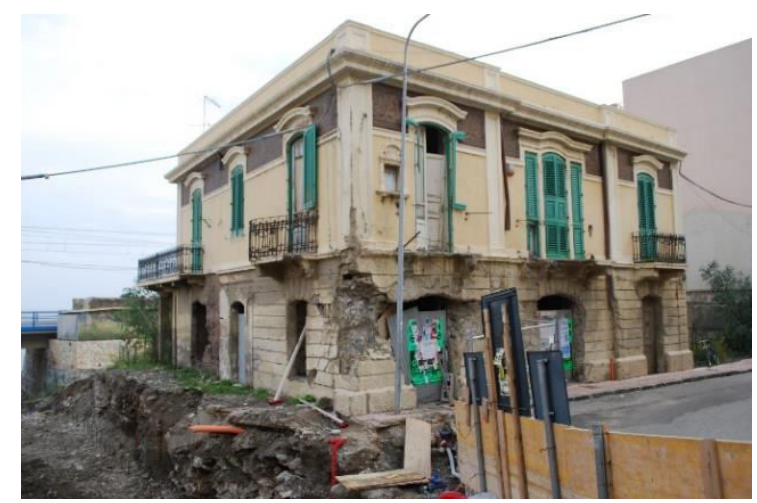

Figure 10. Edifice after the event of October 2009.

During the event of October 2009 the structure was seriously damaged. The Northern wall in principal facade (in front of "Consolare Valeria" road) presents the major damages in correspondence of the corner with Eastern wall, the upper-right corner of the left door and the right side of the middle door. Also the wall that is positioned parallel to the Racinazzi Torrent has suffered major damage in the wall panel to the left of the window in the corner with Northern wall. Moreover, a small dependent structure on this side of the building seems to have been swept away completely by the debris flow. All the doors were carried away by the mud that invaded the ground floor. The balconies of the first level and the parapets were broken and the edifice is not still inhabited.

\section{Vulnerability modeling}

\subsection{Characterization of masonry parameters}

For characterizing the mechanical parameters of the masonry, as used for calibrating the FEM structural model, the authors utilized the results of experimental tests made on analogous buildings, built in the same age and with the same construction technology. For the data that have not been drawn by the experimental tests, the indications of Italian National Standards and literature have been considered. In particular, a compression test was carried out on a masonry panel of $1000 \mathrm{~mm}$ wide. A series of steel elements were interposed in the middle of the panel and connected on both faces of the wall at two metallic plates, positioned over the $\mathrm{RC}$ beam on a bed of mortar, by four dywidag bars. Two hydraulic jacks were interposed between the metallic plates (Figure 4). Each side of the upper half of the panel was instrumented with three vertical transducers. A horizontal transducer was positioned at the centre line of both face of the upper half of the panel (Figure 11). The test was destructive and consisted in several cycles of loading and unloading with increasing the maximum values of the vertical compression load (Spinella et al. 2014).

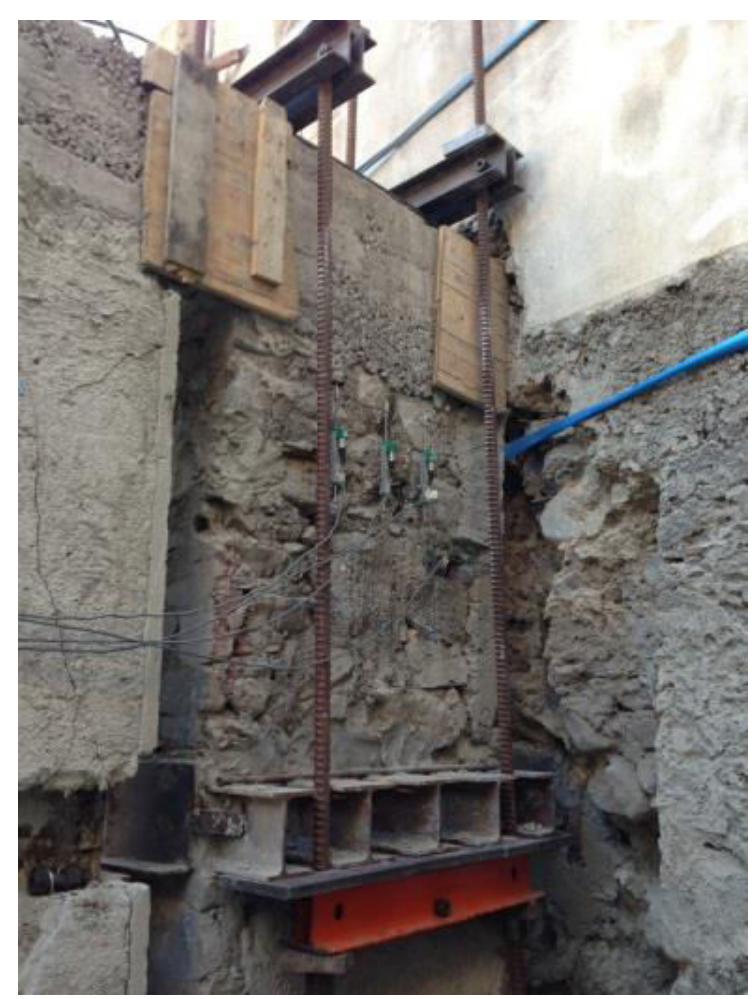

Figure 11. Test setup for panel in compression.

The experimental tests provided the unit weight $\mathrm{w}=$ $20 \mathrm{kN} / \mathrm{m}^{3}$, the compressive strength capacity $\sigma_{\mathrm{c}}=0.89$ $\mathrm{MPa}$. For the other parameters the Italian National Technical Standards and Guidelines have been utilized by using the classification with compression strength capacity and typological shape of masonry. In particular shear strength is assumed to be equal to $\tau_{0}=0.1 \mathrm{MPa}$ (according to Italian Code (IBC 2008) for masonry walls with $\sigma_{\mathrm{m}}<7.5 \mathrm{MPa}$ ); the Young's modulus is equal to $\mathrm{E}=$ $1000 \sigma_{\mathrm{c}}=890 \mathrm{MPa}$; and the shear modulus is assumed to be equal to $\mathrm{G}=0.4 \mathrm{E}=356 \mathrm{MPa}$ that corresponds to Poisson's ratio $v=0.25$.

\subsection{Finite element modelling of the building}

In order to model the building in question, the elastic 2D shell element of the SAP2000 software (Figure 12) with a rectangular mesh discretization of dimension almost $250 \times 250 \mathrm{~mm}$ has been used. The thickness of the external walls in the first story are equal to $750 \mathrm{~mm}$. Figure $12 \mathrm{a}$ shows the damaged wing in the building. As it can be seen in Figure 12, the intact structure shows a small dependence in the correspondence of the eastern wall. We have not modelled this small structure because a) it seems to be built in a different time with respect to the rest of the structure and its connection to the primary 
structural system of the building was not guaranteed; b) it seems to be swept away by the tangential component of the dynamic forces exerted by the flow. Figure 13 demonstrate the geometric configuration of the building analysed herein with the exact position of all openings. As it can be seen in Figure 12, the nodes in the base of building are fixed.

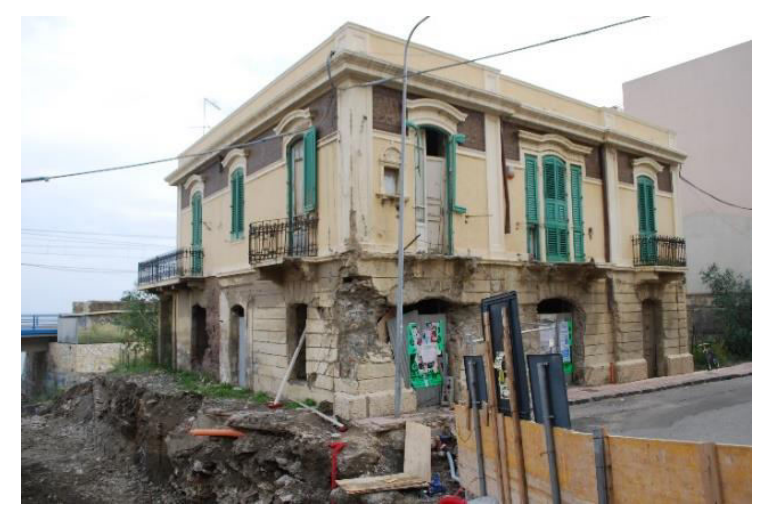

(a)

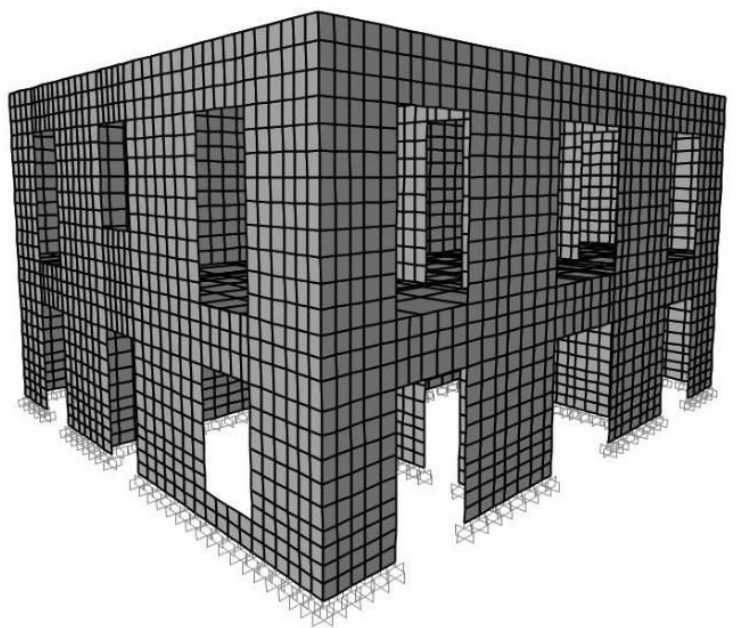

(b)

Figure 12. a) Damaged building, b) 3D structural model in SAP 2000.

It is worth mentioning that this model depicts the local damages caused by the flow. The consequences of an eventual local reduction/loss in load-bearing capacity (in the correspondence of the damaged wall panel) on the overall stability of the building have been evaluated.

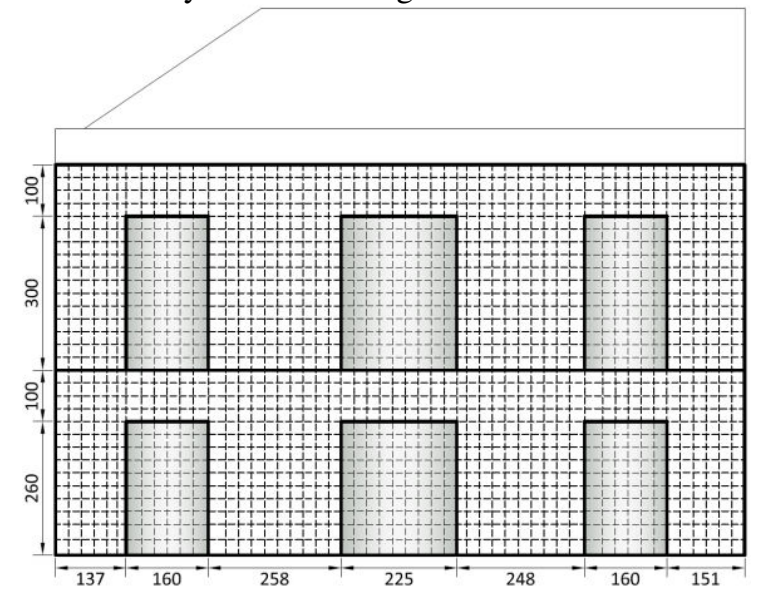

(a)

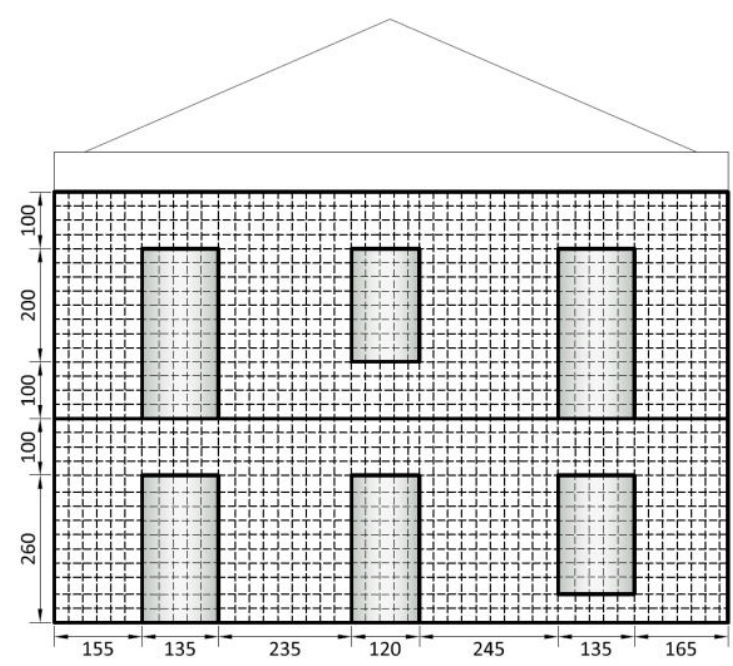

(b)

Figure 13. a) Northern wall, b) Eastern wall.

The structural analyses are based on the hypothesis that the openings (doors and windows) have remained closed during the flow. The reactions due to debris flow that acts on doors and windows are calculated and applied as forces to the door and windows' sides (assuming that doors and windows are just connected to two sides and they and their connections are not going to fail during the event and transfer all the loads to the sides). This hypothesis is only partially true; that is the openings were most probably closed at the beginning (given the fact that the event has taken place after midnight) but the evidence suggests that they were washed away during the event. It is to note that this hypothesis is conservative with respect to the alternative hypothesis that the doors and windows were not present. In the latter case, the hydrostatic forces will decrease due to the fact that the flow will infiltrate and fill the buildings' interior space. The analyses are done by neglecting the tangential component of hydrodynamic forces that act parallel to the wall panel. The effect of the accidental impact of the flow borne large objects has been considered in this analysis. As it can be seen in Figure 14 it seems a large pipe has impacted building and it is cause of local damages in the North-Eastern part of the building.

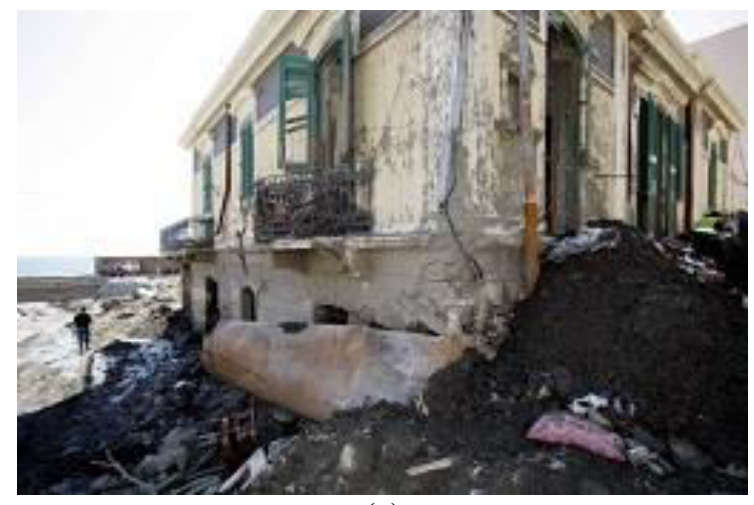

(a) 


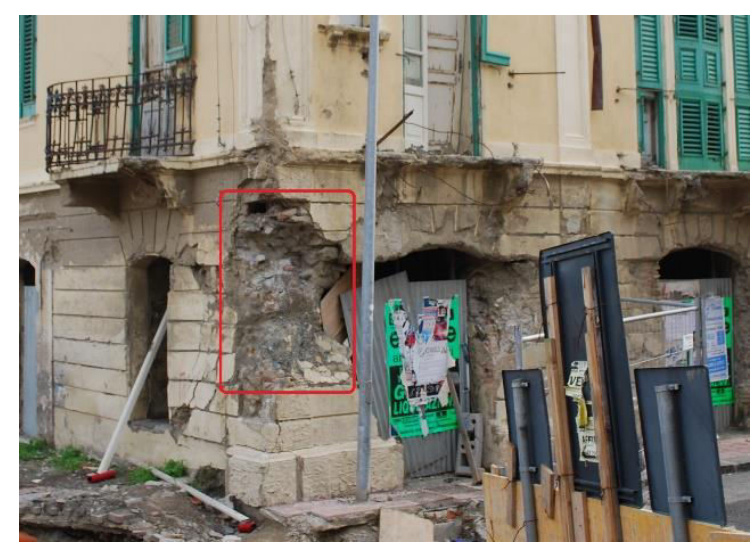

(b)

Figure 14. a) Large pipe that has impacted the building b) The local damage due to impact-type load.

The impact load applied by the pipe has roughly been estimated herein. The weight of the pipe is roughly estimated around $W_{D} \approx 125 \mathrm{kN}$ (based on dimensions of the pipe with respect to dimensions of the building in Figure (14a)), the velocity of object assumed to be equal to the maximum velocity of flow at Northern wall $v_{D} \approx 2$ $\mathrm{m} / \mathrm{s}$ (Figure 6), and duration of the impact is considered around $t \approx 0.1 \mathrm{sec}$. So, the estimated impact load is equal to:

$$
F_{D I}=\frac{\left(125 / 9.81^{) \times 2}\right.}{0.1}=250 \mathrm{kN}
$$

\subsection{The debris-flow action}

The load conditions considered for the case study building is composed of two main load categories: dead loads and debris-flow loads. Self-weight of walls is considered automatically as distributed for each shell element. Also, the following loads are considered: 7.5 $\mathrm{kN} / \mathrm{m}^{2}$ for floor weight (that includes structural, nonstructural and live loads); $4 \mathrm{kN} / \mathrm{m}^{2}$ in order to consider the weight of the roof.

The maximum debris-flow actions are obtained through the analysis procedure described in previous section. In fact, as it can be depicted in Figure 5, Figure 6 and Figure 7, the propagation of the debris flow by means of finite elements provides the depths, velocity modules and phases for each element in the mesh. Assuming a linear profile for the hydrostatic component, a constant value for the hydro-dynamic profile, and a concentrated force for impact. The total forces exerted to the exposed walls can be evaluated from Equation (3) and (3). Figure 15 demonstrates the footprint of the flow depth envelope on both walls of the building that is exposed to debris flow.

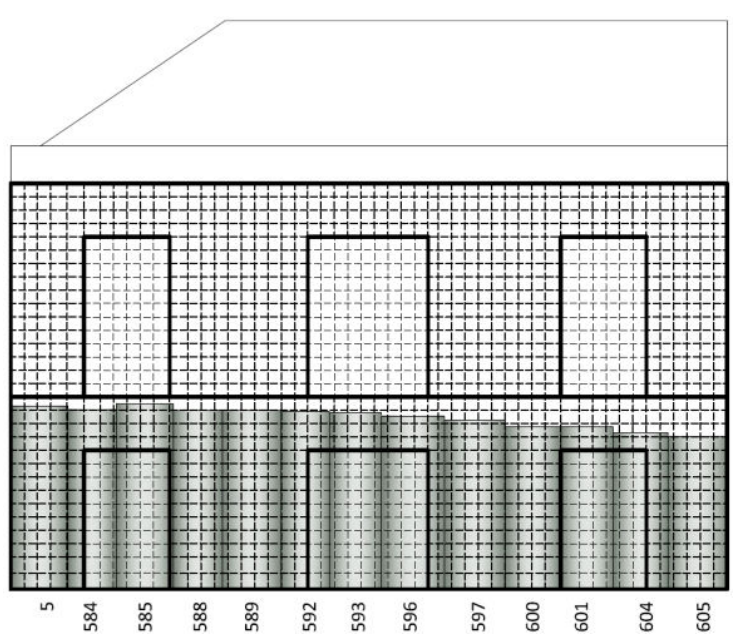

(a)

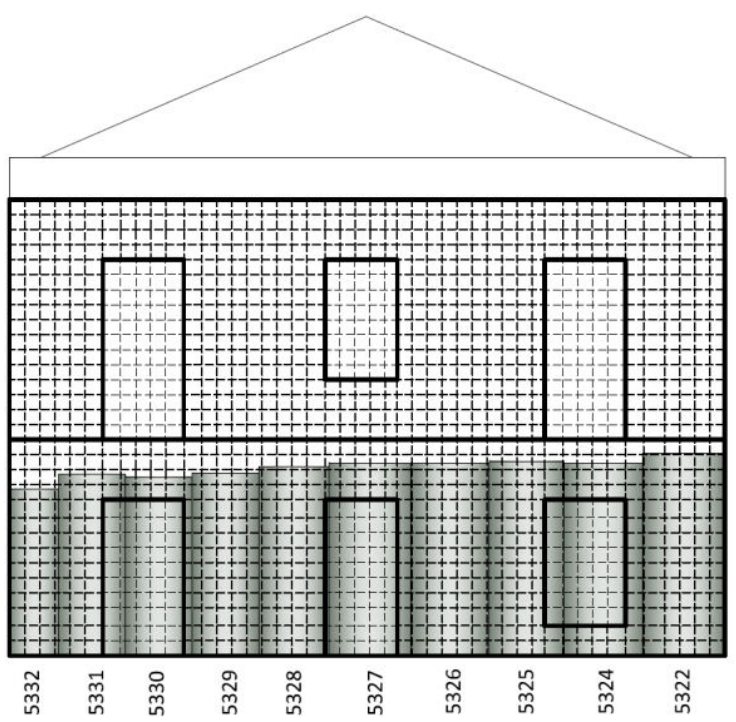

(b)

Figure 15. Maximum depth of the debris flow for a) The Northern wall, b) The Eastern wall.

Figure 16 shows the graphical scheme of hydrostatic pressure, hydrodynamic pressure, and impact load due to debris flow on the building.

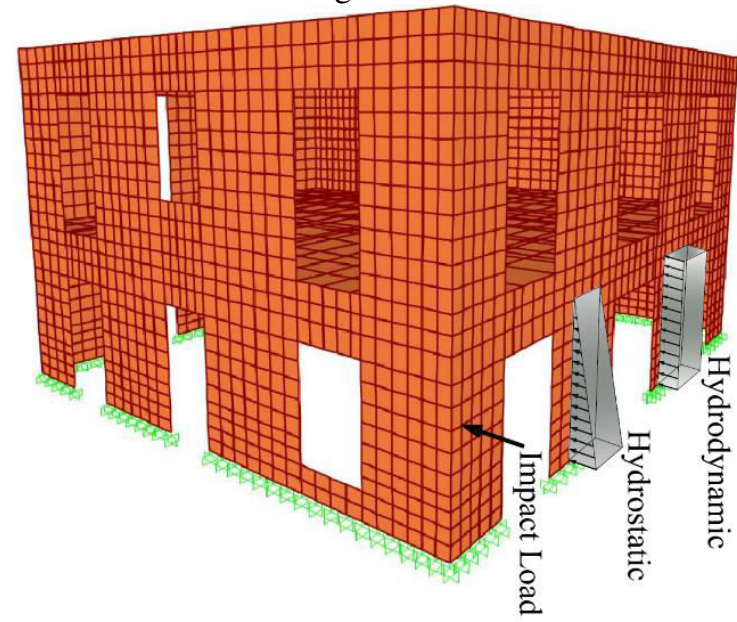

Figure 16. The schematic representation of hydrostatic and hydrodynamic components of debris flow pressure and the impact load due to flow borne object. 


\subsection{The structural response parameter}

Based on the geometric and mechanical model described in the previous section, a linear static analysis is performed with SAP2000 in order to evaluate the stress distributions in the wall panels. The response parameter used herein for monitoring the damage in the wall panel is the demand to capacity ratio denoted as $\mathrm{Y}(\mathrm{Y}=\mathrm{D} / \mathrm{C})$ (i.e., the maximum demand to capacity ratio). The choice of a dimension-less demand to capacity ratio as the response parameter provides the possibility of comparing various actions (i.e. stress, force, shear, moment, deformations, etc.), indicating the un-safe structural behavior by $\mathrm{Y}>1$.

\subsection{In-plane diagonal cracking shear failure}

We have used the Turnšek and Čačovič (1971) criterion for determining the $\mathrm{Y}_{\text {in-shear }}$ ratio for the in-plane shear force when the wall panel is subjected to a combination of the lateral (in-plane) and gravity loading.

The force-based demand to capacity ratio is defined herein as is defined below:

$$
Y_{\text {in-shear }}=\frac{R_{\text {shear }}}{R_{\text {shear-res }}}
$$

Where $R_{\text {shear }}$ is maximum shear force demand in the section under consideration and $R_{\text {shear-res }}$ is ultimate shear strength of section and is calculated as:

$$
R_{\text {shear-res }}=\tau_{\lim } \times A
$$

Where $\tau_{\text {lim }}$ is the maximum shear stress allowed and $A$ is cross sectional area.

The limit state surface (Betti et al. 2012; Turnšek and Čačovič 1971) has been calculated according to Italian Code (IBCC 2009) as reported below:

$$
\tau_{\lim }=\tau_{0} \cdot \sqrt{1+\frac{\sigma_{0}}{1.5 \cdot \tau_{0}}}
$$

Where $\tau_{0}$ is the maximum pure shear strength (without axial load); $\sigma_{0}$ is the average compressive axial stress applied on the section.

\subsection{In-plane sliding shear failure}

The demand to capacity ratio $Y_{\text {in-sliding }}$ for the in-plane sliding shear force is defined as:

$$
Y_{\text {in-sliding }}=\frac{R_{\text {sliding }}}{R_{\text {sliding-res }}}
$$

Where $R_{\text {sliding }}$ is maximum sliding shear force demand in the section under consideration and $R_{\text {sliding-res }}$ is ultimate sliding shear strength and is calculated using this formula:

$$
R_{\text {sliding-res }}=l^{\prime} t\left(f_{v 0}+0.4 \sigma_{n}\right)
$$

Where $t$ is wall thickness; $f_{v 0}$ is shear strength without axial load; $\sigma_{n}=P /\left(l^{\prime} t\right)$ average compressive axial stress on the compression area; and $l$ is the length of compressed area and can be evaluated as follows:

$$
l^{\prime}=3\left(\frac{l}{2}-\frac{M}{P}\right)
$$

Where $l$ is length of section; $M$ and $P$ are bending moment and axial load acting on section respectively.

\subsection{Out-of-plane flexural failure}

We have also verified the possibility of out-of-plane flexural instability at the base of the walls by calculating the following demand to capacity ratio:

$$
Y_{o p-f}=\frac{M_{l}}{M_{R}}
$$

In which $M_{l}$ is the flexural moment due to hydraulic load condition in the unit width of wall and $M_{R}$ is the flexural moment resistance of unit width of wall calculated as follows (Priestley 1985)

$$
\begin{aligned}
& M_{R}=P \cdot\left(\frac{t-a}{2}\right) \\
& a=\frac{P}{0.85 \sigma_{c}}
\end{aligned}
$$

where $P$ is the axial force acting on unit width of wall; $\sigma_{c}$ is the compressive strength of the masonry; $t$ is the wall thickness; and $a$ is the depth of compression zone in panel cross section orthogonal to the axial load.

\subsection{Out-of-plane sliding shear failure}

Given the thickness of the wall panels in the first story $(750 \mathrm{~mm})$, the possibility of out-of-plane sliding shear failure is verified by neglecting the influence of axial forces and possible buckling. The $Y_{\text {op-sliding }}$ ratio for the out-of-plane sliding shear failure is calculated using the following relationship:

$$
Y_{\text {op-sliding }}=\frac{R_{\text {sliding }}}{R_{\text {sliding-res }}}
$$

Where $R_{\text {sliding }}$ is maximum out-of-plane sliding shear demand and $R_{\text {sliding-res }}$ is ultimate sliding shear strength without considering the effects of axial force:

$$
R_{\text {sliding-res }}=l t\left(f_{v k 0}\right)
$$

Where $l$ wall length; $f_{v k 0}$ is shear strength without axial load; and $t$ is thickness of section.

\subsection{The damage pattern in the walls}

Figure 17 illustrates the damage pattern in the Northern and Eastern walls of the building due to inplane shear stresses (the $\mathrm{Y}_{\text {in-shear }}$ is calculated in the previous section from Equation (5)). Since Equation (7) gives the average shear strength on the whole section, it must be compared with the average shear stress acting on the section. So, to compare the shear stresses calculated by SAP 2000 which are not the average value on a given section, the maximum allowed shear stress $\tau_{\text {lim }}$ (Equation (7)) is multiplied by the ratio of $\left(\tau_{\max } / \tau_{\text {average }}\right)$ estimated to 
be around 1.5 and then compared with the results of SAP 2000 .

It can be observed that the Northern wall remains in the safe zone although some parts of the wall are close to the failure surface. On the other hand, the Eastern wall shows that the panel to the left of the window crosses the failure surface. It is important to note that the mathematical model used herein has limited capability in tracing the failure pattern in the walls. That is, the presumable stress re-distribution in the wall after the cracks progressively form cannot be captured by this linear-elastic model. Nevertheless, the model is reasonably capable of indicating where and how the wall starts to have problems due to stress concentration.

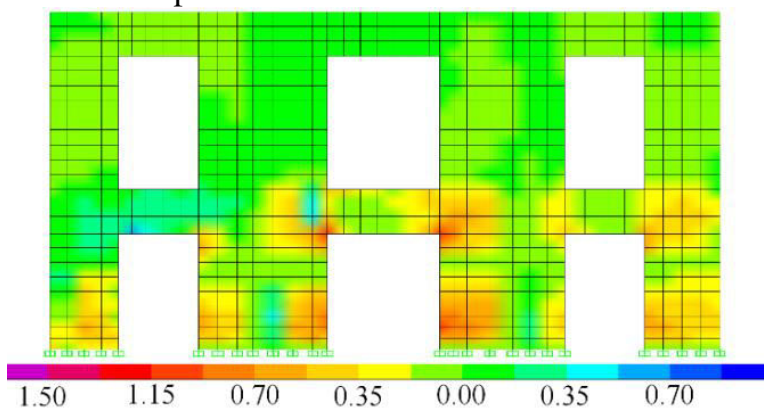

(a)

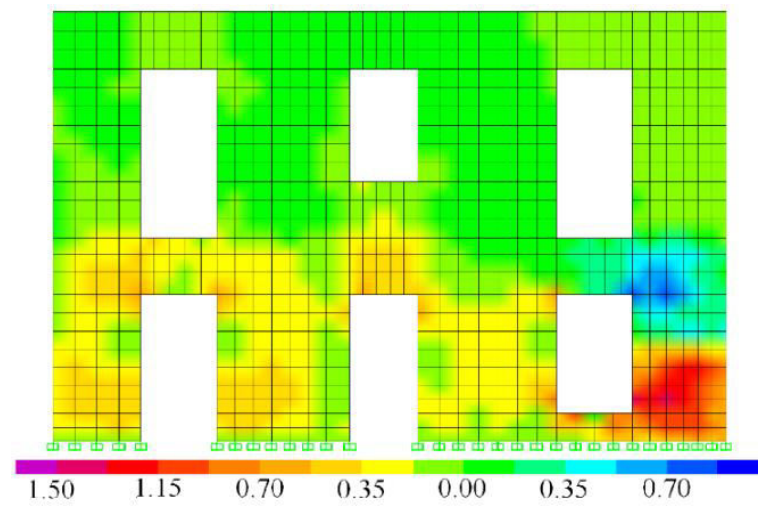

(b)

Figure 17. In-Plane ( $\left.\mathrm{Y}_{\text {in-shear }}\right)$ axial-shear demand to capacity ratio for a) The Northern wall, b) The Eastern wall.

In this section the in-plane sliding shear strength for the most critical pier of building (Eastern Wall) is calculated using Equations (9) and (10) as follows:

$$
\begin{aligned}
& l^{\prime}=3\left(\frac{1.65}{2}-\frac{90}{250}\right)=1.4 \mathrm{~m} \\
& \sigma_{n}=\frac{250}{1.4 \times 0.75}=40 \mathrm{kN} / \mathrm{m}^{2} \\
& R_{\text {sliding-res }}=1.4 \times 0.75(100+0.4 \times 240)=205 \mathrm{kN}
\end{aligned}
$$

and in-plane diagonal cracking shear strength of the same pier is:

$$
\begin{aligned}
& \sigma_{0}=\frac{250}{1.65 \times 0.75}=200 \mathrm{kN} / \mathrm{m}^{2} \\
& \tau_{\lim }=100 \times \sqrt{1+\frac{200}{1.5 \times 100}}=150 \mathrm{kN} / \mathrm{m}^{2}
\end{aligned}
$$

$$
R_{\text {shear-res }}=150 \times(1.65 \times 0.75)=185 \mathrm{kN}
$$

Since the in-plane sliding shear strength of panel (for the most critical case) is greater than diagonal cracking shear strength $\left(\mathrm{R}_{\text {sliding-res }} \approx 205 \mathrm{kN}>\mathrm{R}_{\text {shear-res }} \approx 185 \mathrm{kN}\right)$, so sliding shear does not govern the failure of the panel and diagonal cracking shear is critical action in the panel.

Figure 18 shows the $Y_{o p-f}$ distribution for out-of-plane base moment for the wall panels. As it was expected, given the width of the wall, the out-of-plane over-turning moment does not seem to be as critical as the in-plane shear failure modes considered before.

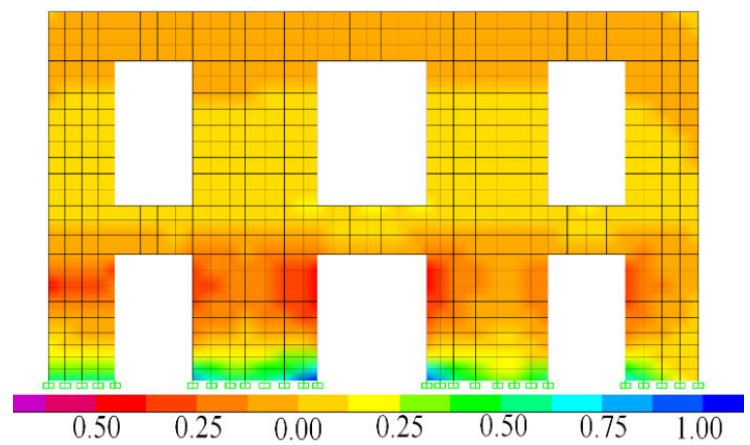

(a)

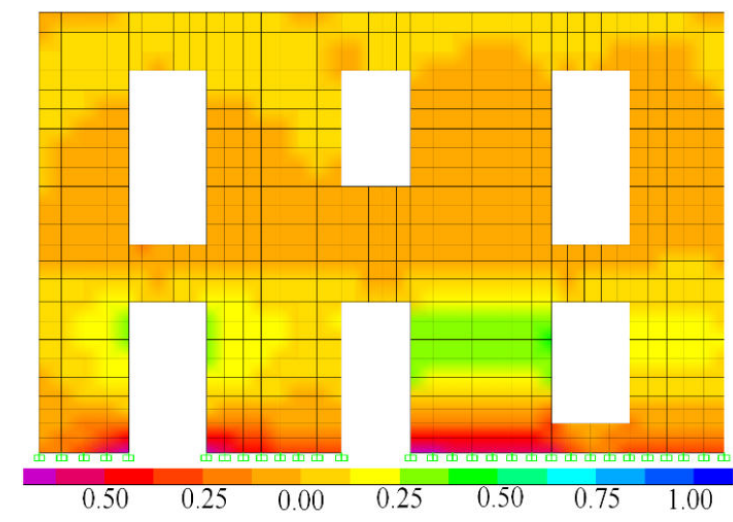

(b)

Figure 18. Out-of-Plane $\left(\mathrm{Y}_{\mathrm{op}-\mathrm{f}}\right)$ moment demand to capacity ratio for a) The Northern wall, b) The Eastern wall.

Figure 19 shows the damage pattern in the wall due to out-of-plane shear stresses $\left(Y_{o p-s l i d i n g}\right.$ is calculated in the previous section from Equation Equation (13)). It can be seen that the Northern wall is more affected by the outof-plane stress. In other words, it seems that it suffers more from the direct hydraulic forces exerted by the flow. This is while the Eastern wall seems to be affected more drastically by the reactions transferred from the orthogonal Northern wall. 


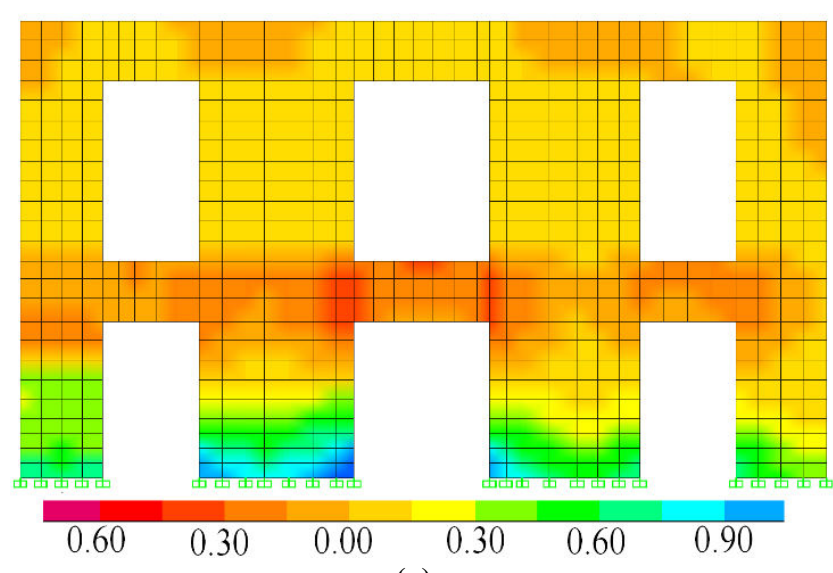

(a)

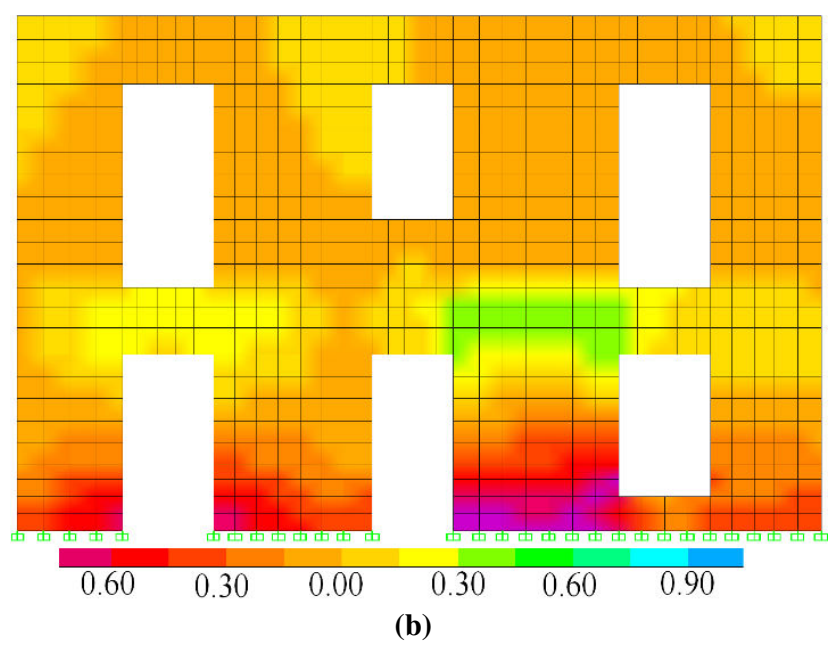

Figure 19. Out-of-Plane ( $\mathrm{Y}_{\mathrm{op} \text {-sliding }}$ ) shear demand to capacity ratio for a) The Northern wall, b) The Eastern wall.

Recall that the analyses do not consider the component of the hydro-dynamic forces parallel to the wall panels. These forces seem to be small for the Northern wall. However, they seem to be quite large for the Eastern wall. This is backed both by the hydraulic calculations and the evidence provided by the balcony railing that is completely deformed by the flow. We have presumed that the hydrodynamic component parallel to the Eastern wall has mainly contributed to washing away the small dependence on the side of the building and has had little effect on the damage pattern observed on the rightmost panel in this wall.

\subsection{Comparison with the observed damage}

The results in terms of shear demand to capacity ratio are visually compared with the damage observed after the debris-flow. Figure 20 highlights the visual signs of cracks on the Eastern wall panel and compares it with the in-plane stress pattern in the finite-element model. It can be seen that the finite element model manages to capture the in-plane shear failure in the rightmost panel. The figure shows also the deformation of the balcony railing due to the flow (discussed in the previous section).

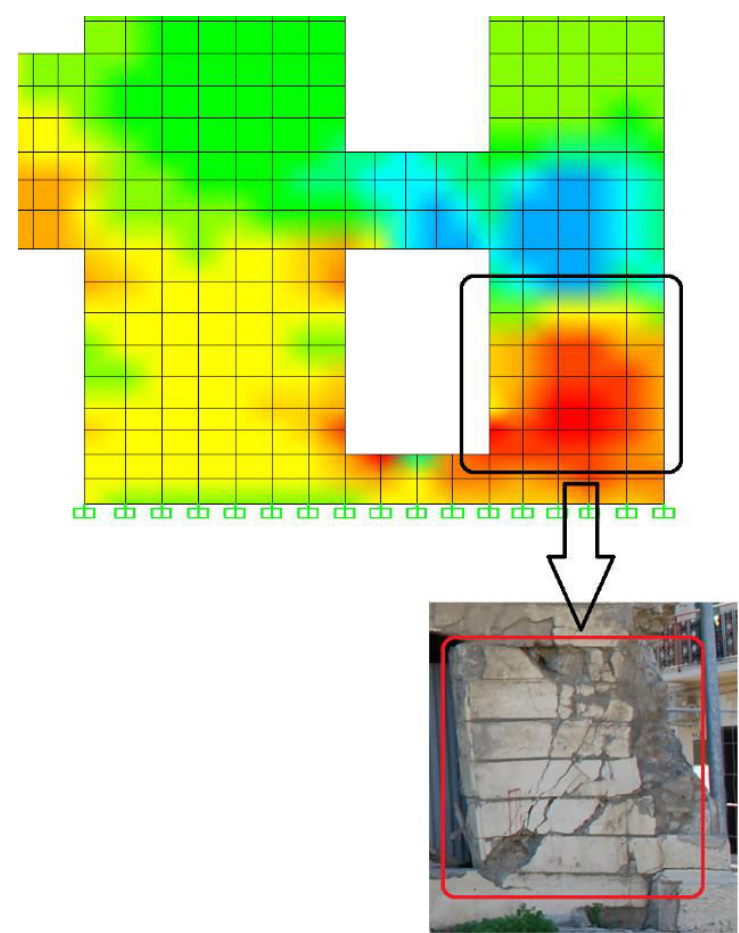

(a)

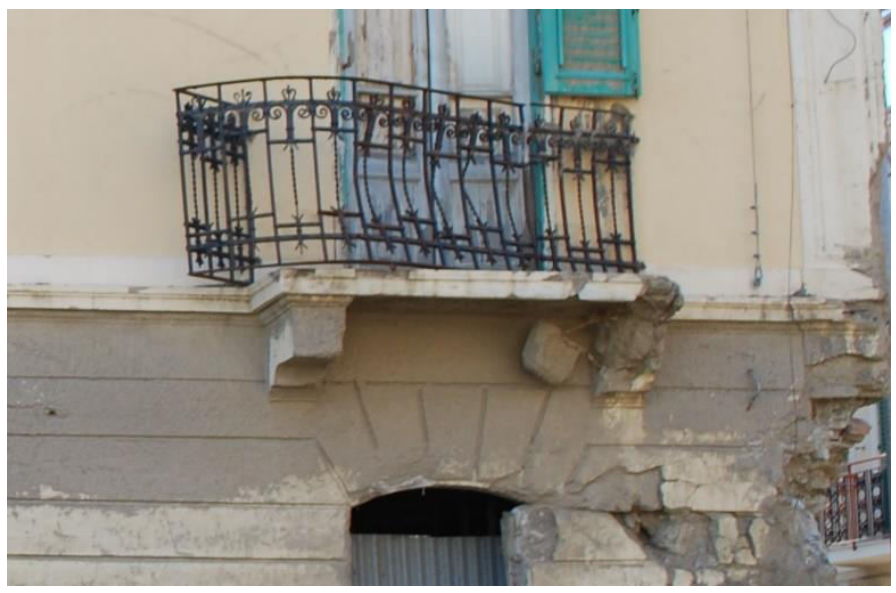

(b)

Figure 20. a) Comparison between analysis result and the observed damage for the Eastern wall, b) Deformation of the balcony in the eastern side of building.

Damage on the Northern wall seems to be due to the effects of impact load as discussed before. As can be observed, the Northern wall shows signs of major damage in correspondence of the corner with Eastern wall.

The Figure demonstrates that the observed damage state is congruent with the results of the FEM analysis (as much as an elastic model can do). The damage pattern observed in the walls, apart from being a direct result of the exceptional hydraulic forces exerted by the flow and the poor mechanical properties of the masonry, is also dictated by the configuration of the openings (as the weak points) in the walls.

\section{Conclusion}


The flash-flood debris event of the October 1st 2009 in Scaletta Zanclea has led to loss of life and significant damage to the constructed environment. Focusing the attention on an eighteenth masonry building (damaged and upgraded after the Messina-Reggio Calabria Earthquake of 1906), we have strived to reconstruct analytically the damages incurred to this building due to the debris flow event of 2009. The flash flood/debris flow seems to have washed away completely a small dependence on the Eastern side, and to have partially washed away the doors and windows. As a result, the debris invaded the ground floor of the building. The building shows signs of in-plane shear failure followed by out-of-plane failure in the rightmost panel of the Eastern wall. Moreover, the Northern wall shows visual signs of damage in the corner in correspondence with the Eastern wall.

In order to re-construct the damages incurred to the building due to the flash flood/debris flow event, hydrostatic and hydrodynamic force envelopes, calculated via a 2D hydrodynamic finite element model specifically designed for debris flow spatial propagation, have been applied to the building in question (assuming perfect coherence between static and dynamic maxima). The hydrodynamic model used for the debris flow propagation proved to be well suited for these specific applications. The finite element approach showed its capability in describing the complex geometries of the urban environments as the distributed nature of the 2D code allows deriving a reliable spatial distribution of debris flow actions. As matter of fact, the flooded areas obtained with the 2D propagation model are consistent with those surveyed after the October 2009 event. A three-dimensional model of the building has been constructed using the elastic two-dimensional shell elements. The resulting model manages the capture the most significant damages in the building due to a disastrous combination of poor mechanical properties and high hydrostatic and hydrodynamic forces.

\section{Acknowledgements}

This work was supported in part the National Operative Program Project METROPOLIS 2014-16.

\section{References}

1. Akbas, S., Blahut, J., and Sterlacchini, S. (2009). Critical assessment of existing physical vulnerability estimation approaches for debris flows. Landslide processes: from geomorphological mapping to dynamic modelling. CERG Editions, Strasbourg, pp. 229-233.

2. Alcoverro, J., Corominas, J., and Gómez, M. (1999). The Barranco de Arás flood of 7 August 1996 (Biescas, Central Pyrenees, Spain). Engineering Geology, 51(4), 237-255.

3. Aronica, G., Brigandì, G., Marletta, C., and Manfrè, B. (2009). Hydrological and hydraulic analysis of the flash flood event on 25 October 2007 in NorthEastern part of Sicily, Italy.
4. Aronica G.T., Brigandì G., \& Morey N. (2012). Flash floods and debris flow in the city area of Messina, North-East part of Sicily, Italy in October 2009: the case of the Giampilieri catchment. Natural Hazard and Earth System Sciences, 12(5), 12951309.

5. Aronica, G., Tucciarelli, T., and Nasello, C. (1998). 2D multilevel model for flood wave propagation in flood-affected areas. Journal of water resources planning and management, 124(4), 210-217.

6. Aronica, G. T., Biondi, G., Brigandì, G., Cascone, E., Lanza, S., and Randazzo, G. (2012). Assessment and mapping of debris-flow risk in a small catchment in eastern Sicily through integrated numerical simulations and GIS. Physics and Chemistry of the Earth, Parts A/B/C, 49, 52-63.

7. Bagnold, R. A. (1954). Experiments on a gravity-free dispersion of large solid spheres in a Newtonian fluid under shear. Proc., Proceedings of the Royal Society of London A: Mathematical, Physical and Engineering Sciences, The Royal Society, pp. 49-63.

8. Bell, R., and Glade, T. (2004). Quantitative risk analysis for landslides? Examples from Bíldudalur, NW-Iceland. Natural Hazards and Earth System Science, 4(1), 117-131.

9. Betti, M., Galano, L., Petracchi, M., and Vignoli, A. (2012). Seismic Strength of Unreinforced Masonry Walls: Effects of the $b$ Shape Factor of the Shear Failure Criterion with Diagonal Cracking.

10. Borga, M., Boscolo, P., Zanon, F., and Sangati, M. (2007). Hydro meteorological analysis of the 29 August 2003 flash flood in the Eastern Italian Alps. Journal of Hydrometeorology, 8(5), 1049-1067.

11. Botija, M. d. C. L., de Batlle, J., Rigo, T., and Barriendos, M. (2001). Las inundaciones del 10 junio del 2000 en Cataluña. Ingeniería del agua, 8(1).

12. Brufau, P., Garcia-Navarro, P., Ghilardi, P., Natale, L., and Savi, F. (2000). 1D mathematical modelling of debris flow. Journal of Hydraulic Research, 38(6), 435-446.

13. Chow, V. T., Maidment, D. R., and Mays, L. W. (1988). Applied hydrology.

14. De Risi, R., Jalayer, F., De Paola, F., Iervolino, I., Giugni, M., Topa, M., Mbuya, E., Kyessi, A., Manfredi, G., and Gasparini, P. (2013). Flood risk assessment for informal settlements. Natural hazards, 69(1), 1003-1032.

15. Faella, C., and Nigro, E. (2003). Dynamic impact of the debris flows on the constructions during the hydrogeological disaster in Campania-1998: failure mechanical models and evaluation of the impact velocity. Proc., Proceedings of the international conference on FSM, Naples, Italy, pp. 179-186.

16. Fuchs, S., Heiss, K., and Hübl, J. (2007). Towards an empirical vulnerability function for use in debris flow risk assessment. Natural Hazards and Earth System Science, 7(5), 495-506.

17. Gaume, E., Bain, V. and Bernardara, P. (2008). Primary Flash flood Data. Work Package 1 Report for HYDRATE, EC Project No. GOCE-CT-2004505420. 
18. Gaume, E., Livet, M., Desbordes, M., and Villeneuve, J.-P. (2004). Hydrological analysis of the river Aude, France, flash flood on 12 and 13 November 1999. Journal of Hydrology, 286(1), 135154.

19. Georgakakos, K. P. (1986). On the Design of National, Real-Time Warning Systems with Capability for Site-Specific, Flash-Flood Forecasts. B Am Meteorol Soc, 67(10), 1233-1239.

20. Haugen, E. D., and Kaynia, A. M. (2008). Vulnerability of structures impacted by debris flow. Landslides and Engineered Slopes: From the Past to the Future, Vols 1 and 2, pp. 381-387.

21. Huet, P., Martin, X., Prime, J.-L., Foin, P., Laurain, C., and Cannard, P. (2003). Retour d'expérience des crues de septembre 2002 dans les départements du Gard, de l'Hérault, du Vaucluse, des Bouches-duRhône, de l'Ardèche et de la Drôme. Rapport IGE (Inspection Générale de l'Environnement).

22. IBC (2008). Italian Building Code, DM 14.01. 2008: Norme tecniche per le costruzioni. Italian Ministry of Infrastructures and Transportation, Rome.

23. IBCC (2009). Italian Building Commentary Code, Circolare n. 617 del 02.02. 2009: Istruzioni per l'applicazione delle «Nuove Norme Tecniche per le Costruzioni» di cui al decreto ministeriale 14 gennaio 2008. Transportation.

24. Kelman, I., and Spence, R. (2004). An overview of flood actions on buildings. Engineering Geology, 73(3), pp. 297-309.

25. Larsen, M., Wieczorek, G., Eaton, L., Morgan, B., and Torres-Sierra, H. (2002). Natural hazards on alluvial fans; The Venezuela debris flow and flash flood disaster.

26. Mavrouli, O., Fotopoulou, S., Pitilakis, K., Zuccaro, G., Corominas, J., Santo, A., Cacace, F., De Gregorio, D., Di Crescenzo, G., and Foerster, E. (2014). Vulnerability assessment for reinforced concrete buildings exposed to landslides. Bulletin of Engineering Geology and the Environment, 73(2), 265-289.

27. Naef, D., Rickenmann, D., Rutschmann, P., and McArdell, B. (2006). Comparison of flow resistance relations for debris flows using a one-dimensional finite element simulation model. Natural Hazards and Earth System Science, 6(1), 155-165.

28. Nigro, E., and Faella, C. (2010). Landslides as a secondary event of earthquakes and eruptions. Proc., Urban Habitat Constructions Under Catastrophic Events: Proceedings of the COST C26 Action Final Conference, CRC Press, 153.

29. Priestley, M. N. J. (1985). Seismic behavior of unreinforced masonry walls. Bulletin of the New Zealand national society for earthquake engineering, Vol 18, No 2, pp. 191-205.

30. Parisi, F., Lignola, G., Augenti, N., Prota, A., and Manfredi, G. (2011). Nonlinear behavior of a masonry subassemblage before and after strengthening with inorganic matrix-grid composites. Journal of Composites for Construction, 15(5), 821832.
31. Quan Luna, B., Blahut, J., Van Westen, C., Sterlacchini, S., van Asch, T. W., and Akbas, S. (2011). The application of numerical debris flow modelling for the generation of physical vulnerability curves. Natural Hazards and Earth System Science, 11(7), 2047-2060.

32. Restrepo, P., Cannon, S., Laber, J., Jorgensen, D., and Werner, K. NOAA/USGS demonstration flashflood and debris-flow early-warning system for recently burned areas in Southern California, USA. Proc., 7th International Conference on Geomorphology. Australia.

33. Smith, D. (1994). Flood damage estimation- A review of urban stage-damage curves and loss functions. Water S. A., 20(3), 231-238.

34. Spinella, N., Colajanni, P., and Recupero, A. (2014). Experimental in situ behaviour of unreinforced masonry elements retrofitted by pre-tensioned stainless steel ribbons. Construction and Building Materials, 73, 740-753.

35. Sweeney, T. L. (1992). Modernized areal flash flood guidance, US Department of Commerce, National Oceanic and Atmospheric Administration, National Weather Service, Office of Hydrology.

36. Takahashi, T. (1991). Debris flow, Balkema.

37. Turnšek, V., and Čačovič, F. (1971). Some experimental results on the strength of brick masonry walls. Proc., Proceedings of the 2nd international brick-masonry conference. British Ceramic Society, Stoke-on-Trent, pp. 149-156.

38. Zanchetta, G., Sulpizio, R., Pareschi, M., Leoni, F., and Santacroce, R. (2004). Characteristics of May 56, 1998 volcaniclastic debris flows in the Sarno area (Campania, southern Italy): relationships to structural damage and hazard zonation. Journal of volcanology and geothermal research, 133(1), 377-393. 